Tsudik A. V., Glushkov A. V., Ternovsky V. B., Zaichko P. A.

Odesa National Maritime Academy, Didrikhsona str. 4, Odesa, 65001

Odesa State Environmental University, L'vovskaya str.15, Odesa-16, 65016, Ukraine

E-mail: tsudikav@gmail.com

\title{
ADVANCED COMPUTING TOPOLOGICAL AND DYNAMICAL INVARIANTS OF RELATIVISTIC BACKWARD-WAVE TUBE TIME SERIES IN CHAOTIC AND HYPERCHAOTIC REGIMES
}

\begin{abstract}
The advanced results of computing the dynamical and topological invariants (correlation dimensions values, embedding, Kaplan-York dimensions, Lyapunov's exponents, Kolmogorov entropy etc) of the dynamics time series of the relativistic backward-wave tube with accounting for dissipation and space charge field and other effects are presented for chaotic and hyperchaotic regimes. It is solved a system of equations for unidimensional relativistic electron phase and field unidimensional complex amplitude. The data obtained make more exact earlier presented preliminary data for dynamical and topological invariants of the relativistic backwardwave tube dynamics in chaotic regimes and allow to describe a scenario of transition to chaos in temporal dynamics.
\end{abstract}

\section{Introduction}

Powerful generators of chaotic oscillations of microwave range of interest for radar, plasma heating in fusion devices, modern systems of information transmission using dynamic chaos and other applications. Among the most studied of vacuum electronic devices with complex dynamics are backward-wave tubes (BWT), for which the possibility of generating chaotic oscillations has been theoretically and experimentally found [1-20]. The BWT is an electronic device for generating electromagnetic vibrations of the superhigh frequencies range. Authors [6] formally considered the possible chaos scenario in a single relativistic BWT. Authors $[4,5]$ have numerically studied dynamics of a non-relativistic BWT, in particular, phase portraits, statistical quantifiers for a weak chaos arising via period-doubling cascade of self-modulation and the same characteristics of two non-relativistic backward-wave tubes. The authors of [4-7] have solved the equations of nonstationary nonlinear theory for the O-type BWT without account of the spatial charge, relativistic effects, energy losses etc. It has been shown that the finitedimension strange attractor is responsible for chaotic regimes in the BWT. The multiple studies [1-13], increasing the beam current in the system implemented complex pattern of alternation of regular and chaotic regimes of generation, completes the transition to a highly irregular wideband chaotic oscillations with sufficiently uniform continuous spectrum.

In this work we have performed an advanced numerical analysis and modelling and presented some results of computing the dynamical and topological invariants (correlation dimensions values, embedding, KaplanYork dimensions, Lyapunov's exponents, Kolmogorov entropy etc) of the dynamics time series of the relativistic backward-wave tube with accounting for dissipation and space charge field and other effects are presented for chaotic and hyperchaotic regimes. The system of equations for unidimensional relativistic electron phase and field unidimensional complex amplitude is numerically solved using the Runge-Cutta method. The data presented make more exact the preliminary data for dynamical and topological invariants of the relativistic backward-wave tube dynamics in chaotic regimes and allow to describe a scenario of transition to chaos in temporal dynamics.

\section{Relativistic model and some results}

As the key ideas of our technique for nonlinear analysis of chaotic systems have been in 
details presented in refs. [9-28], here we pay attention only on the kew and some new elements. Below we follow to the version of a standard non-stationary theory [9], however, despite the above cited papers we take into account a number of effects, namely, influence of space charge, dissipation, the waves reflections at the ends of the system and others (a modification of model of Refs.[5-13]).

The standard relativistic dynamics is described system of equations for unidimensional relativistic electron phase $\theta\left(\zeta, \tau, \theta_{0}\right)$ (which moves in the interaction space with phase $\theta_{0}$ $\left(\theta_{0} \in[0 ; 2 \pi]\right)$ and has a coordinate $\zeta$ at time moment $\tau$ ) and field unidimensional complex amplitude $F(\zeta, \tau)=\tilde{E} /\left(2 \beta_{0} U C^{2}\right)$ as [11]:

$$
\begin{aligned}
& \partial^{2} \theta / \partial \zeta^{2}=-L^{2} \gamma_{0}^{3}\left[\left(1+\frac{1}{2 \pi N} \partial \theta / \partial \zeta\right)^{2}-\beta_{0}^{2}\right]^{3 / 2} \\
& \operatorname{Re}\left[F \exp (i \theta)+\frac{4 Q C}{i k} \sum_{k=1}^{M} I_{k} \exp (i k \theta)\right]
\end{aligned}
$$

$$
\begin{gathered}
\partial F / \partial \tau-\partial F / \partial \zeta+d F=-L \tilde{I} \\
I_{k}=-\frac{1}{\pi} \int_{0}^{2 \pi} e^{-i k \theta} d \theta_{0}
\end{gathered}
$$

with the corresponding boundary and initial conditions. The dynamical system studied has several controlling parameters which are characteristic for distributed relativistic electron-waved self-vibrational systems: i) electric length of an interaction space $\mathrm{N}$; ii) bifurcation parameter $L=2 \pi \mathrm{CN} / \gamma_{0}$ (here Cis the known Piers parameter) ; iii) relativistic factor, which is determined as:

$$
\gamma_{0}=\left(1-\beta_{0}^{2}\right)^{-1 . / 2}
$$

It should be also noted that an influence of reflections leads to the fact that bifurcational parameter $\mathrm{L}$ begins to be dependent on the phase $\varphi$ of the reflection parameter (see discussion regarding it in $[7,8]$ ).

\section{Chaos-dynamic approach to analysis of time series}

The basic idea of the construction of our approach to prediction of chaotic properties of complex systems is in the use of the traditional concept of a compact geometric att (CGA) in which evolves the measurement data, plus the neural networks (NNW) algorithm implementation [14-38].

Really, one should consider some scalar measurements $s(n)=s\left(t_{0}+n \Delta t\right)=s(n)$, where $t_{0}$ is the start time, $\Delta t$ is the time step, and $n$ is the number of the measurements. The main task is to reconstruct phase space using as well as possible information contained in $s(n)$. To do it, the method of using time-delay coordinates by Packard et al [28] can be used. The direct using lagged variables $s(n+\tau)$ (here $\tau$ is some integer to be defined) results in a coordinate system where a structure of orbits in phase space can be captured. A set of time lags is used to create a vector in $d$ dimensions, $\mathbf{y}(n)=[s(n), s(n+\tau)$, $s(n+2 \tau), . ., s(n+(d-1) \tau)]$, the required coordinates are provided. Here the dimension $d$ is the embedding dimension, $d_{E}$. To determine the proper time lag at the beginning one should use the known method of the linear autocorrelation function (ACF). The alternative additional approach is provided by the average mutual information (AMI) method as an approach with so called nonlinear concept of independence.

The further next step is to determine the embedding dimension, $d_{E}$, and correspondingly to reconstruct a Euclidean space $R^{d}$ large enough so that the set of points $d_{A}$ can be unfolded without ambiguity. The dimension, $d_{E}$, must be greater, or at least equal, than a dimension of attractor, $d_{A}$, i.e. $d_{E}>d_{A}$. To reconstruct the attractor dimension and to study the signatures of chaos in a time series, one could use such methods as the correlation integral algorithm (CIA) by Grassberger 
and Procaccia [32] or the false nearest neighbours (FNN) method by Kennel et al [27. The principal question of studying any complex chaotic system is to build the corresponding prediction model and define how predictable is a chaotic system. The new element of our approach is using the NNW algorithm in forecasting nonlinear dynamics of chaotic systems $[7,14,15]$.

The fundamental parameters to be computed are the Kolmogorov entropy (and correspondingly the predictability measure as it can be estimated by the Kolmogorov entropy), the Lyapunov's exponents (LE), the Kaplan-Yorke dimension (KYD) etc. The LE are usually defined as asymptotic average rates and they are related to the eigenvalues of the linearized dynamics across the attractor. Naturally, the knowledge of the whole LE allows to determine other important invariants such as the Kolmogorov entropy and the attractor's dimension. The Kolmogorov entropy is determined by the sum of the positive LE.

The estimate of the dimension of the attractor is provided by the Kaplan and Yorke conjecture:

$d_{L}=j+\sum_{i=1}^{j} \lambda_{i} /\left|\lambda_{j+1}\right|$,

where $j$ is such that $\sum_{i=1}^{j} \lambda_{i}>0$ and $\sum_{i=1}^{j+1} \lambda_{i}<0$, and the LE are taken in descending order.

In Fig. 1 we present the flowchart of the combined chaos-geometric and NNW computational approach to nonlinear analysis and prediction of dynamics of any system [1,11,14-48]. All calculations are carried out with using the PC Codes "Geomath", "Superatom", "Quantum Chaos" (e.g. [1,1626,39-48]).
I. General analysis of the dynamical problem, processing dynamical variable series for studied complex system (preliminary general analysis of dynamics, evolutionary differential equations treating,...)

II. Chaos-geometric method: assessment of the presence of chaos:

1. The Gottwald-Melbourne test: $K \rightarrow 1$ - chaos;

2. Fourier decompositions, irregular nature of change - chaos;

3. Spectral analysis, Energy spectra statistics, the Wigner distribution, the spectrum of power, "Spectral rigidity";

III. The geometry of phase space. Fractal Geometry:

4. Computation time delay $\tau$ using ACF or AMI;

5. Determining embedding dimension $d_{E}$ by the CIA method or FNN points;

6. Calculation multi-fractal spectra. Wavelet analysis;

\section{Prediction model:}

7. Computing global LE: $\lambda_{\alpha}$; KYD $d_{L}$, average predictability measure $\operatorname{Pr}_{\max }$;

8. Determining the number of FNN points for the best prediction results;

9. Methods of nonlinear prediction: nonlinear parameterized function; NNW; optimized trajectories (propagators) algorithms, ...;

Figure 1. Flowchart of the combined chaosgeometric approach and NNW to nonlinear analysis and prediction of chaotic dynamics of the complex systems (devices)

\section{Illustrative results and conclusions}

In Figure 2 we present the numerical temporal dependence of the output signal amplitude of the relativistic backward-wave tube for parameter $\mathrm{L}=6.1$ (b) (see other details, e.g. [7]). 


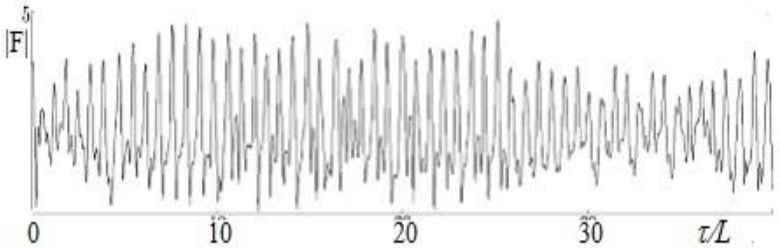

Figure 2. Numerical temporal dependence of the output signal amplitude of the relativistic BWT for $\mathrm{L}=6.1$.

In Table 1 we present our data on the correlation dimension $\mathrm{d}_{2}$, the embedding dimension determined based on the algorithm of false nearest neighboring points $\left(\mathrm{d}_{\mathrm{N}}\right)$ with percentage of false neighbors $(\%)$ calculated for different values of time lag $\tau$. The values of the time lag are also listed in this table for the both regimes as chaotic as hyperchaotic one.

Table 1.

Correlation dimension $\mathrm{d}_{2}$, the dimension of the attachment determined based on the algorithm of false nearest neighboring points $\left(d_{N}\right)$ with percentage of false neighbors $(\%)$ calculated for different values of time lag $\tau$

\begin{tabular}{|c|c|c|c|c|c|}
\hline \multicolumn{3}{|c|}{ Chaos (I) } & \multicolumn{3}{c|}{ Hyperchaos (II) } \\
\hline$\tau$ & $\mathrm{d}_{2}$ & $\left(\mathrm{~d}_{\mathrm{N}}\right)$ & $\tau$ & $\mathrm{d}_{2}$ & $\left(\mathrm{~d}_{\mathrm{N}}\right)$ \\
\hline 60 & 3.62 & $\begin{array}{c}5 \\
(5.6)\end{array}$ & 67 & 7.23 & $\begin{array}{c}10 \\
(13)\end{array}$ \\
\hline 6 & 3.13 & $\begin{array}{c}4 \\
(1.1)\end{array}$ & 10 & 6.44 & $\begin{array}{c}8 \\
(2.2)\end{array}$ \\
\hline 8 & 3.11 & $\begin{array}{c}4 \\
(1.2)\end{array}$ & 12 & 6.42 & $\begin{array}{c}8 \\
(2.2)\end{array}$ \\
\hline
\end{tabular}

In Table 2 we list the results of computing the Lyapunov's exponents, the, Kolmogorov entropy $\mathrm{K}_{\mathrm{entr}}$. For the studied series there are positive and negative values of the Lyapunov's exponents. Naturally, an availability of the positive values of the Lyapunov's exponents is a characteristic feature of the chaotic dynamics of the studied systems. It shoyld be noted that the latter is an example of distributed multiparametric system that provides the known difficulties under studying of such systems.
Table 2.

The Lyapunov's exponents for the backwardwave tube time series in the chaotic $(\mathrm{L}=4.2)$ and hyperchaotic regimes ( $\mathrm{L}=6.1): \lambda_{1}-\lambda_{4}$ in descending order and $K$ is the Kolmogorov entropy

\begin{tabular}{|c|c|c|c|c|c|}
\hline Regime & $\lambda_{1}$ & $\lambda_{2}$ & $\lambda_{3}$ & $\lambda_{4}$ & $K$ \\
\hline Chaos & 0.261 & 0.0001 & -0.0004 & -0.528 & 0.26 \\
\hline $\begin{array}{c}\text { Hyper } \\
\text { chaos }\end{array}$ & 0.514 & 0.228 & 0.0000 & -0.0002 & 0.74 \\
\hline
\end{tabular}

\section{References}

1. Glushkov, A.V.; Prepelitsa, G.P.; Svinarenko, A.A. ; Zaichko, P.A. Studying interaction dynamics of the non-linear vibrational systems within non-linear prediction method (application to quantum autogenerators) In Dynamical Systems Theory; Awrejcewicz, J., Kazmierczak, M., Olejnik, P., Mrozowski, J., Eds.; Wyd. Politech. Łódz.: Łódz, 2013; Vol T1, pp 467-477.

2. Ignatenko, A.V.; Buyadzhi, A.; Buyadzhi, V.; Kuznetsova,A.; Mashkantsev, A.; Ternovsky, E. Nonlinear chaotic dynamics of quantum systems: molecules in an electromagnetic field// Adv. Quant. Chem. 2018,78 doi.org/10.1016/bs.aiq.2018.06.006.

3. Ginsburg, H. S.; Kuznetsov, S.P.; Fedoseyev, T.N. Theory of transients in relativistic BWO. Izv. Vuzov. Ser. Radiophys. 1978, 21, 1037-1052.

4. Ginzburg, N.S.; Zaitsev, N.A.; Ilyakov, E.; Kulagin, V.I.; Novozhilov, Yu. Rosenthal P., Sergeev V., Chaotic generation in backward wave tube of the megawatt power level. Journ. of Techn.Phys. 2001, 71, 73-80.

5. Kuznetsov A.P., Kuznetsov S.P., Ryskin N.M., Isaeva O.B., Non-linearity: From oscillations to chaos.-Moscow: NIS RHD.-2006.

6. Kuznetsov A.P., Shirokov A.P., Discretre model of relativistic backward-wave 
tube. Russian J.of Phys. Ser.PND. 1997. 5, 76-83.

7. Kuznetsov S.P., Trubetskov D.I., Chaos and hyperchaos in backward-wave tube. Russian Journ.of Phys. Ser.Radiophys.2004, XLVII(5), 1-8

8. Ryskin N.M., Titov V.N., The transition to the development of chaos in a chain of two unidirectionally-coupled backwardwave tubes. Journ.Techn.Phys. 2003. 73, 90-94.

9. Glushkov, A.V.; Buyadzhi, V.V.; Ternovsky V.B. Geometry of Chaos: Consistent combined approach to treating of chaotic self-oscillations in backwardwave tube. Proc. Intern. Geometry Center. 2013, 6(2), 6-12.

10. Ternovsky V.B., Geometry and Dynamics of a Chaos: Modelling non-linear processes in relativistic backward-wave tubes chain. Proc. of Int. Geom. Center. 2014, 7(3), 79-86

11. A.V. Glushkov, A.V. Tsudik, D.A. Novak, O.B. Dubrovsky, Chaotic dynamics of relativistic backward-wave tube with accounting for space charge field and dissipation effects: New effects. Photoelectronics. 2018. 27, 44-51.

12. Levush, B.; Antonsen, T.M.; Bromborsky, A.; Lou, W.R.; Carmel, Y. Theory of relativistic backward wave oscillator with end reflections. IEEE Trans. on Plasma Sci. 1992, 20, 263-280.

13. Ryskin, N.M.; Titov, V.N. Selfmodulation and chaotic regimes of generation in a relativistic backwardwave oscillator with end reflections. Radiophys. and Quant.Electr. 2001, 44, 793-806.

14. Glushkov, A.V.; Khetselius, O.Yu.; Svinarenko, A.A.; Prepelitsa, G.P. Energy approach to atoms in a laser field and quantum dynamics with laser pulses of different shape. In Coherence and Ultrashort Pulsed Laser Emission. Duarte, F.J., Ed.; InTech: Rijeka, 2010, 159-186.

15. Levush, B.; Antonsen, T.; Bromborsky, A.; Lou, W. Relativistic backward wave oscillator: theory and experiment. Phys.Fluid. 1992, B4, 2293-2299.
16. Glushkov, A.V. Methods of a Chaos Theory. OSENU: Odessa, 2012.

17. Glushkov, A.V. Atom in an electromagnetic field. KNT: Kiev, 2005.

18. Glushkov, A.V.; Khetselius, O.Yu.; Brusentseva, S.V.; Zaichko, P.A.; Ternovsky, V.B. Studying interaction dynamics of chaotic systems within a nonlinear prediction method: Application to neurophysiology In Advances in Neural Networks, Fuzzy Systems and Artificial Intelligence, Series: Recent Advances in Computer Engineering; Balicki, J., Ed.; WSEAS Press: Gdansk, 2014; Vol 21, pp 69-75.

19. Khetselius, O.Yu. Forecasting evolutionary dynamics of chaotic systems using advanced non-linear prediction method In Dynamical Systems Applications; Awrejcewicz, J., Kazmierczak, M., Olejnik, P., Mrozowski, J., Eds.; Wyd. Politech. Łódz.: Łódz, 2013; Vol T2, pp 145-152..

20. Glushkov, A.V.; Malinovskaya, S.V.; Gurnitskaya, E.P.; Khetselius, O.Yu.; Dubrovskaya, Yu.V. Consistent quantum theory of recoil induced excitation and ionization in atoms during capture of neutron. J. Phys.: Conf. Ser. 2006, 35, 425-430.

21. Khetselius, O.Yu. Hyperfine structure of atomic spectra. Astroprint: Odessa, 2008.

22. Khetselius, O.Yu. Quantum structure of electroweak interaction in heavy finite Fermi-systems. Astroprint: Odessa, 2011.

23. Glushkov, A.V. Relativistic Quantum theory. Quantum mechanics of atomic systems. Astroprint: Odessa, 2008.

24. Glushkov, A.V., Khetselius, O.Yu., Svinarenko, A.A., Buyadzhi, V.V. Spectroscopy of autoionization states of heavy atoms and multiply charged ions. TEC: Odessa, 2015

25. Glushkov, A.V. Relativistic and correlation effects in spectra of atomic systems. Astroprint: Odessa, 2006.

26. Glushkov, A.V.; Prepelitsa, G.P.; Svinarenko, A.A. ; Zaichko, P.A. Studying interaction dynamics of the non-linear vi- 
brational systems within non-linear prediction method (application to quantum autogenerators) In Dynamical Systems Theory; Awrejcewicz, J., Kazmierczak, M., Olejnik, P., Mrozowski, J., Eds.; Wyd. Politech. Łódz.: Łódz, 2013; Vol T1, pp 467-477.

27. Abarbanel, H.; Brown, R.; Sidorowich, J; Tsimring, L. The analysis of observed chaotic data in physical systems. Rev. Mod. Phys. 1993, 65, 1331- 1392.

28. Packard, N.; Crutchfield, J; Farmer, J.; Shaw, R. Geometry from a time series Phys. Rev. Lett. 1988, 45, 712-716.

29. Kennel, M.; Brown, R.; Abarbanel, H. Determining embedding dimension for phase-space reconstruction using a geometrical construction. Phys. Rev. A. 1992, 45, 3403-3412.

30. Packard N., Crutchfield J., Farmer J., Shaw R., Geometry from a time series//Phys Rev Lett.-1988.-Vol.45.P.712-716.

31. Gallager, R. Information theory and reliable communication. N.-Y., 1986.

32. Grassberger, P. ; Procaccia, I. Measuring the strangeness of strange attractors. Physica D. 1983, 9, 189-208.

33. Theiler, J.; Eubank, S.; Longtin, A.; Galdrikian, B.; Farmer, J. Testing for nonlinearity in time series: The method of surrogate data. Physica D. 1992, 58, 77-94.

34. Glushkov, A.V.; Malinovskaya, S.V.; Loboda, A.V.; Shpinareva, I.M.; Gurnitskaya, E.P.; Korchevsky, D.A. Diagnostics of the collisionally pumped plasma and search of the optimal plasma parameters of $\mathrm{x}$-ray lasing: calculation of electron-collision strengths and rate coefficients for Ne-like plasma. J. Phys.: Conf. Ser. 2005, 11, 188-198.

35. Taken, F. Detecting strange attractors in turbulence. Lecture notes in mathematics (Springer) 1981, 898, 366-381.

36. Glushkov, A.V.; Buyadzhi, V.V.; Ponomarenko, E.L. Geometry of Chaos: Advanced approach to treating chaotic dynamics in some nature systems// Proc. Intern. Geom. Center. 2014 7(1),24-30.
37. Sano, M.; Y. Sawada, Y. Measurement of the Lyapunov spectrum from chaotic time series. Phys Rev.Lett. 1995, 55, 1082-1085

38. Rusov V., Glushkov A., Vaschenko V., Korchevsky D., Ignatenko A. Stochastic dynamics of the atomic systems in the crossed electric and magnetic field: the rubidium atom recurrence spectra. Bull.of Kiev Nat. Univ. 2004, N4, 433.

39. Khetselius, O. Relativistic perturbation theory calculation of the hyperfine structure parameters for some heavy-element isotopes. Int. J. Quant.Chem. 2009, 109, 3330-3335.

40. Khetselius, O. Relativistic calculation of the hyperfine structure parameters for heavy elements and laser detection of the heavy isotopes. Phys.Scr. 2009, T135, 014023.

41. Glushkov, A.; Gurskaya, M.; Ignatenko, A.; Smirnov, A.; Serga, I.; Svinarenko, A.; Ternovsky E. Computational code in atomic and nuclear quantum optics: Advanced computing multiphoton resonance parameters for atoms in a strong laser field. J. Phys.: Conf. Ser. 2017, 905, 012004.

42. Buyadzhi, V., Zaichko, P., Antoshkina, O., Kulakli, T., Prepelitsa, P., Ternovsky, V., Mansarliysky, V. Computing of radiation parameters for atoms and multicharged ions within relativistic energy approach: Advanced Code. J. Phys.: Conf. Ser. 2017, 905(1), 012003.

43. Svinarenko, A., Glushkov, A., Khetselius, O., Ternovsky,V., Dubrovskaya, Yu., Kuznetsova, A., Buyadzhi, V. Theoretical spectroscopy of rare-earth elements: spectra and autoionization resonances. Rare Earth Element, InTech. 2017, 83-104.

44. Glushkov A.V., Khetselius O.Yu., Loboda A.V., Ignatenko A., Svinarenko A., Korchevsky D., Lovett L., QED Approach to Modeling Spectra of the Multicharged Ions in a Plasma: Oscillator and Electron-ion Collision Strengths. AIP Conference Proceedings.-2008. 1058, 175-177 
45. Glushkov, A., Khetselius, O., Svinarenko A.A., Buyadzhi, V.V., Ternovsky, V., Kuznetsova, A., Bashkarev, P. Relativistic perturbation theory formalism to computing spectra and radiation characteristics: application to heavy element. Recent Studies in Perturbation Theory. InTech. 2017, 131-150.

46. Glushkov, A.V.; Malinovskaya, S.V.; Prepelitsa, G.P.; Ignatenko, V. Manifestation of the new laser-electron nuclear spectral effects in the thermalized plasma: QED theory of co-operative laserelectron-nuclear proces-ses. J. Phys.: Conf. Ser. 2005, 11, 199-206.
47. Ivanova, E.P., Ivanov, L.N., Glushkov, A., Kramida, A. High order corrections in the relativistic perturbation theory with the model zeroth approximation, Mg-Like and Ne-Like Ions. Phys. Scripta 1985, 32, 513-522.

48. Prepelitsa, G.; Glushkov, A.V.; Lepikh, Ya.; Buyadzhi, V.; Ternovsky, V.; Zaichko, P. Chaotic dynamics of nonlinear processes in atomic and molecular systems in electromagnetic field and semiconductor and fiber laser devices: new approaches, uniformity and charm of chaos. Sensor Electr. and Microsyst.Techn. 2014, 11, 43-57.

Tsudik A.V., Glushkov A.V., Ternovsky V.B., Zaichko P.A.

\section{ADVANCED COMPUTING TOPOLOGICAL AND DYNAMICAL INVARIANTS OF RELATIVISTIC BACKWARD-WAVE TUBE TIME SERIES IN CHAOTIC AND HYPERCHAOTIC REGIMES}

Summary. The advanced results of computing the dynamical and topological invariants (correlation dimensions values, embedding, Kaplan-York dimensions, Lyapunov's exponents, Kolmogorov entropy etc) of the dynamics time series of the relativistic backwardwave tube with accounting for dissipation and space charge field and other effects are presented for chaotic and hyperchaotic regimes. It is solved a system of equations for unidimensional relativistic electron phase and field unidimensional complex amplitude. The data obtained make more exact earlier presented preliminary data for dynamical and topological invariants of the relativistic backward-wave tube dynamics in chaotic regimes and allow to describe a scenario of transition to chaos in temporal dynamics.

Key words: relativistic backward-wave tube, chaotic dynamics, non-linear methods 
Цудик А.В., Глушков А.В., Терновский В.Б., Заичко П.А.

\title{
ХАОТИЧЕСКАЯ ДИНАМИКА РЕЛЯТИВИСТСКОЙ ЛАМПЫ ОБРАТНОЙ ВОЛНЫ С УЧЕТОМ ВЛИЯНИЯ ПОЛЯ ПРОСТРАНСТВЕННОГО ЗАРЯДА И ДИССИПАЦИИ: НОВЫЕ ЭФФЕКТЫ
}

\begin{abstract}
Резюме. Представлены уточненные данные вычисления динамических и топологических инвариантов (значения корреляционной размерности, размерности вложения, Каплана-Йорка, показатели Ляпунова, энтропия Колмогорова и др) для временных рядов, характеризующих динамику релятивистской лампы обратной волны с учетом эффектов диссипации, пространственного заряда и др. в хаотическом и гиперхаотическом режимов. Получены решения системы уравнений для одномерной релятивистской фазы электрона и одномерной комплексной амплитуды поля. Полученные данные уточняют ранее представленные данные для динамических и топологических инвариантов динамики релятивистской лампы обратной волны в хаотических режимах и позволяют количественно охарактеризовать сценарий перехода к хаосу во временной динамике.

Ключевые слова: релятивистская лампы обратной волны, хаотическая динамика, нелинейные методы
\end{abstract}

PACS 42.55.-f

Цудік, А.В., Глушков О.В., Терновський В.Б., Заічко П.О.

\section{ХАОТИЧНА ДИНАМІКА РЕЛЯТИВІСТСЬКОЇ ЛАМПИ ЗВЕРНЕНОЇ ХВИЛІ З УРАХУВАННЯМ ВПЛИВУ ПОЛЯ ПРОСТОРОВОГО ЗАРЯДУ ТА ДИСИПА- ЦIї: НОВІ ЕФЕКТИ}

Резюме. Представлені уточнені дані обчислення динамічних і топологічних інваріантів (значення кореляційної розмірності, розмірності вкладення, Каплана-Йорка, показники Ляпунова, ентропія Колмогорова та ін) для часових рядів, що характеризують динаміку релятивістської лампи зверненої хвилі з урахуванням ефектів дисипації, просторового заряду і ін. в хаотичному і гіперхаотичному режимах. Отримані рішення системи рівнянь для одновимірної релятивістської фази електрона і одновимірної комплексної амплітуди поля. Отримані дані уточнюють раніше представлені дані для динамічних і топологічних інваріантів динаміки релятивістської лампи зворотної хвилі в хаотичному режимі і дозволяють кількісно охарактеризувати сценарій переходу до хаосу у часовій динаміці.

Ключові слова: релятивістська лампи зворотної хвилі, хаотична динаміка, нелінійні методи 